\title{
A Case of Symptomatic Diffuse Esophageal Spasm During Multiple Rapid Swallowing Test on High-Resolution Manometry
}

\author{
Eun Mi Lee, MD, Moo In Park, MD*, Won Moon, MD, Kyung Mi Kim, RN, Seun Ja Park, MD and Hyung Hun Kim, MD
}

Department of Internal Medicine, Kosin University College of Medicine, Busan, Korea

Diffuse esophageal spasm (DES) is an uncommon motility disorder of unknown etiology in which the abnormal motility has been offered as a possible cause for the patient's dysphagia or chest pain. Esophageal manometry is the gold standard for the diagnosis of DES and the diagnostic hallmark is identification of simultaneous contractions in at least $20 \%$ of wet swallows, alternating with normal peristalsis. Recently, a new diagnostic technique, high-resolution manometry has been reported to improve the accuracy and detail in describing esophageal function. We report a female patient with intermittent dysphagia and chest pain occurring only when swallowing a large amount of water. On HRM, this patient had esophageal spasms, increased pressurization front velocity attributable to rapid contractile wave front, associated with symptoms, which were provoked by a multiple rapid swallowing test, and thereby was diagnosed with DES.

(J Neurogastroenterol Motil 2010;16:433-436)

Key Words

Chest pain; Esophageal spasm, diffuse; Manometry

\section{Introduction}

Dysphagia and chest pain are commonly encountered problems in gastroenterology. Spasm of esophagus is often suggested as the cause of unexplained chest pain or dysphagia. Once cardiovascular disease and structural disease have been excluded, esophageal manometry should be performed to detect motility disorders as the cause of symptoms. ${ }^{1}$

Diffuse esophageal spasm (DES) is an uncommon motility disorder of unknown etiology in which has been offered as a possible cause for the patient's dysphagia or chest pain. Manometric evaluation of the esophagus is considered to be the gold standard in patients suspected with DES. ${ }^{1}$ The most accepted diagnostic criteria for DES is the presence of simultaneous contractions in at least $20 \%$ of wet swallows, intermixed with normal peristaltic sequences. ${ }^{2}$

Recently, the development of high-resolution manometry (HRM) and topographical displays has yielded new perspectives and insights into esophageal motor functions. ${ }^{3-5} \mathrm{HRM}$ helps to differentiate true esophageal spasm from rapid elevation of the intra-bolus pressure due to focal dysmotility or obstruction. Applying this distinction makes the diagnosis of DES very rare. ${ }^{4,5}$

We diagnosed a female patient with dysphagia and chest pain

Received: September 20, 2010 Revised: October 7, 2010 Accepted: October 10, 2010

(c) This is an Open Access article distributed under the terms of the Creative Commons Attribution Non-Commercial License (http://creativecommons. org/licenses/by-nc/3.0) which permits unrestricted non-commercial use, distribution, and reproduction in any medium, provided the original work is properly cited.

*Correspondence: Moo In Park, MD

Department of Internal Medicine, Kosin University College of Medicine, 34 Amnam-dong, Seo-gu, Busan 602-702, Korea

Tel: +82-51-990-5061, Fax: +82-51-248-5686,E-mail: mipark@kosinmed.or.kr

Financial support: This study was supported in part by Kosin Institute for Medicine.

Conflicts of interest: None. 
which were triggered by swallowing a large amount of water as DES on multiple rapid swallowing testing during HRM.

\section{Case Report}

A 52-year old female patient was admitted to our hospital with complaints of intermittent dysphagia and chest pain for 1 year. She had symptoms on the lower substernal area when swallowing a large amount of water, which were accompanied by chest pain. Chest pain was a sharp and non-radiating and was relieved by transports of swallowed water to the stomach. These symptoms only occurred when guzzling water and not by taking a sip of water or eating. The temperature of water did not show any correlation with her symptoms. Her past history was unremarkable. There was no family history of similar symptoms. She was of normal body weight and had no abnormalities on chest and abdominal physical examination.

Endoscopy of the upper digestive tract was performed in oth-
A

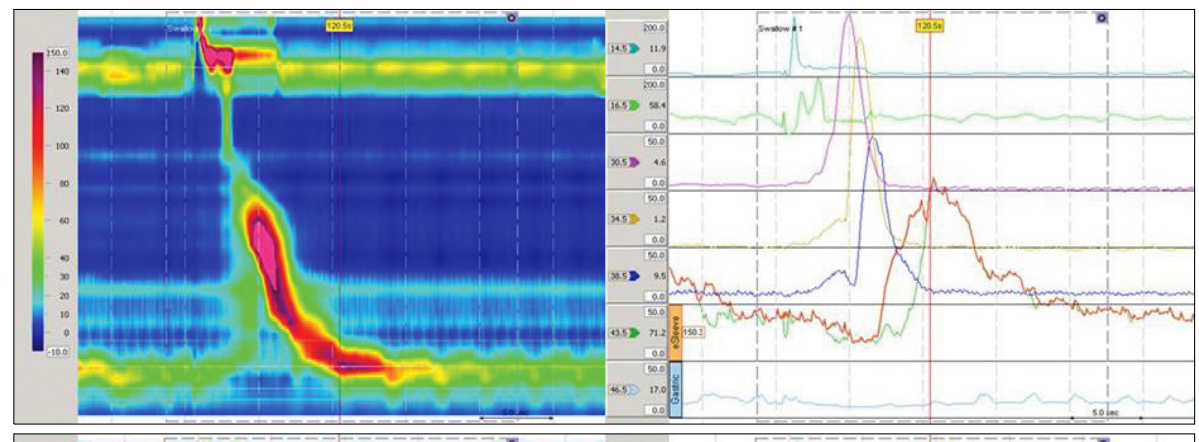

B

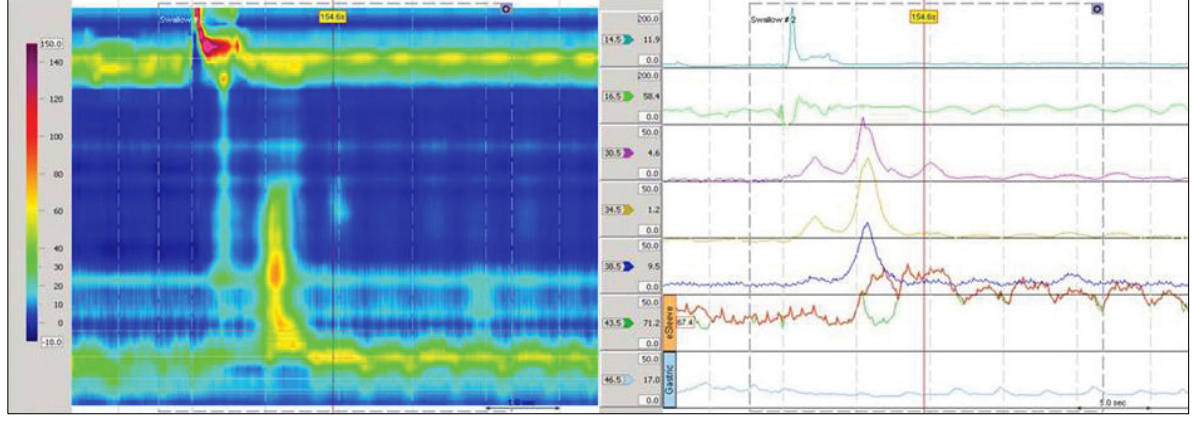

C

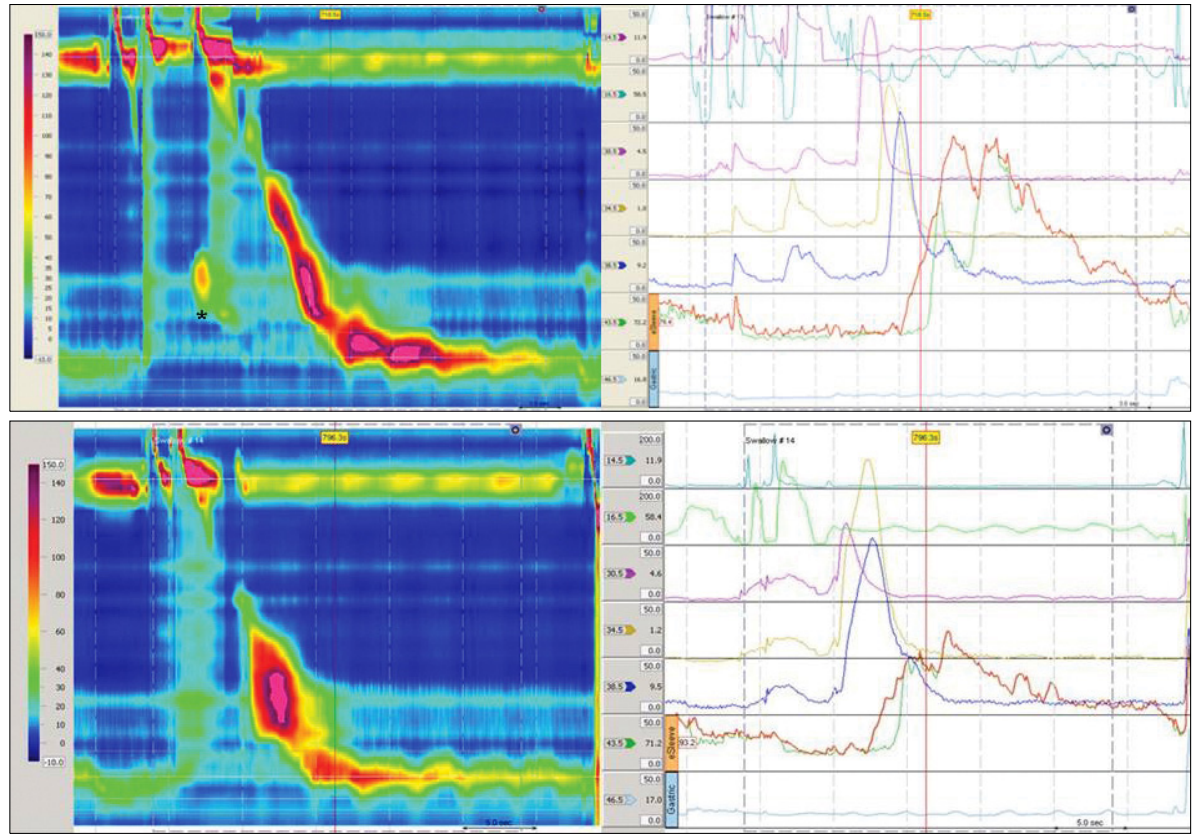

Fiǵure 1. High-resolution manometry (HRM) spatio-temporal plots and concurrent 8 channel conventional manometry line plots (from the same recording). (A) On the first swallow of 5 $\mathrm{mL}$ water, HRM shows a normal peristalsis and the patient has no chest pain and dysphagia. (B) On the second swallow of $5 \mathrm{~mL}$ water, HRM shows no spasm. (C) Normal peristalsis with impaired deglutitive inhibition is seen (asterisk) on 13th swallow of $50 \mathrm{~mL}$ water. The patient felt chest pain and dysphagia with this swallow. (D) On the 14th swallow of $25 \mathrm{~mL}$, she complains symptoms and HRM shows esophageal spasm and normal deglutitive inhibition. 
er hospitals, but there were no abnormal mucosal lesions. Then she was referred to our hospital for further investigation on dysphagia and chest pain. The barium esophagogram showed no abnormalities. 24 hour esophageal impedance-pH monitoring was performed and there were no pathologic regurgitation.

HRM was performed to access the esophageal motility (Fig. 1). On sitting position, 14 times of water swallowing in total was performed. The interval between each swallow was 30 seconds. The patient swallowed $5 \mathrm{~mL}$ of water from the first swallow to the seventh swallow, $10 \mathrm{~mL}$ from the eighth swallow to the 10 th swallow, $15 \mathrm{~mL}$ on the 11 th swallow, $20 \mathrm{~mL}$ on the 12th swallow and $50 \mathrm{~mL}$ on the 13th swallow. On the 14th swallow she tried to drink $100 \mathrm{~mL}$ water, but could swallow only $25 \mathrm{~mL}$. She did not have symptoms from the first to the 10th swallow, but started to complain chest pain and dysphasia when swallowing more than $15 \mathrm{~mL}$. The more water she swallowed, the worse her symptoms got. She complained the most severe symptoms when swallowing $50 \mathrm{~mL}$ of water. Rapid propagated pressurizations were observed at the second, fourth, sixth and seventh swallows, in which pressurization front velocity was measured as 19.1, 8.4, 42.7 and 32.4 $\mathrm{cm} / \mathrm{s}$, respectively. Impaired deglutitive inhibition was observed at the 13th swallow, but peristalsis was normal (Fig. 1C). Except for the 13th swallow, all of the swallows were associated with normal deglutitive inhibitions. The mean gastroesophageal junction pressure was $12.7 \mathrm{mmHg}$. We diagnosed her with DES because more than $20 \%$ of total swallows induced symptomatic esophageal spasms. She was advised to drink water little by little and to take diltiazem $30 \mathrm{mg} 3$ times a day. Thereafter, her symptoms have improved.

\section{Discussion}

This case was interesting in that the chest pain and dysphagia occurred not by drinking a sip of water, but only by drinking a large amount of water. More interestingly, we were able to prove that esophageal spasms were associated with the symptoms when performing HRM with large amount of water swallowing technique and multiple rapid water swallowing technique. Not only were we able to diagnose DES with accuracy, we were also able to observe the esophageal spasms developed with onset of symptoms through multiple rapid swallowing test without any other kind of provocation tests. It is noteworthy that we were able to prove the cause of her symptoms during HRM testing. As far as we know, this is the first report of DES in which symptoms were reproduced during high-resolution esophageal manometry with multi- ple rapid swallowing.

Although many patients with non-obstructive dysphagia and chest pain can be diagnosed accurately by the conventional esophageal manometry, some patients go through difficulties in receiving proper diagnosis. In contrast with conventional esophageal manometry that uses only 3-8 pressure sensors with variable spacing positioned within the esophageal lumen to monitor pressure change following water swallows, a novel technique, HRM is a stationary method that uses an increased number of pressure sensors (up to 36) and topography pressure plot can be developed for visualization of the esophageal pressure and peristalsis. HRM analyzed with pressure topography plots provides greater detail regarding the characteristics of individual contractile segments along with the esophagus. ${ }^{3,4,6}$

The major advantage of HRM with pressure topography compared with conventional manometry is the ability to easily distinguish between the loci of compartmentalized intra-esophageal pressurization (pseudo-spasm) and rapidly propagated esophageal contractions (spasm). ${ }^{4}$ Spastic disorders such as DES or vigorous achalasia, are quite rare by HRM, since the majority of patients so classified by conventional criteria actually exhibit a pseudo-spasm pattern. ${ }^{4}$ However, she had a PFV of more than 8 $\mathrm{cm} / \mathrm{s}$ in more than $20 \%$ of their swallows and met the criteria for a rapidly propagated contraction. Therefore we could diagnose her case as DES.

Several studies suggest that the motility disorders such as DES, nutcracker esophagus and achalasia share a common pathophysiologic mechanism, which involves the alteration in nitric oxide synthesis/degradation or loss of nitric oxide containing inhibitory neurons in the lower esophageal sphincter (LES). The loss of intramural inhibitory neurons leads to the loss of normal peristalsis and inability of the LES to relax properly during swallowing. ${ }^{7-10}$ DES is associated with incomplete LES relaxation, which is likely in a variant case of achalasia. ${ }^{2}$ The fact that the transition from DES to achalasia has been documented and is believed to occur in $3 \%$ to $5 \%$ of patients supports this observation. ${ }^{11,12}$ In this patient, HRM findings showed not only intermittent esophageal spasms with some normal peristalsis but also impaired deglutitive relaxation at the 13th swallow which is a typical feature in achalasia. ${ }^{4}$ Since DES is possible to progress to achalasia, follow-up studies using HRM will be needed to detect the feasible transition in this patient.

This case was notable in that the chest pain and dysphagia develped only after dinking a large amount of water. Cold liquid or food ingestion may precipitate episodes of dysphagia and chest 
pain in patients with spastic esophageal motility disorders. ${ }^{13-15}$ Esophageal manometry during food ingestion has been used as a provocation test in patients with unexplained chest pain, because food ingestion compared with water swallowing precipitates symptoms more frequently. ${ }^{16}$ But this patient did not complain any symptom with eating, and therefore we did not need to test her while swallowing food. A patient showing precipitated esophageal symptoms by the quantity of water swallowed, regardless of the temperature, has not been described before in literature.

Although we do not know the specific mechanism through which an increase of the quantity of water induces symptoms, increment in the quantity of swallowing water may stimulate secondary peristalsis in esophagus more strongly and esophageal spasm could be provoked more easily. We diagnosed a female patient presenting with dysphagia and chest pain induced by swallowing a large amount of water as DES on multiple rapid swallowing testing during HRM.

\section{Acknowledgements}

The authors thank Jin-A Park for assistance in the preparation of the manuscript.

\section{References}

1. Grubel C, Borovicka J, Schwizer W, Fox M, Hebbard G. Diffuse esophageal spasm. Am J Gastroenterol 2008;103:450-457.

2. Pandolfino JE, Kahrilas PJ; American Gastroenterological association. AGA technical review on the clinical use of esophageal manometry. Gastroenterology 2005;128:209-224.

3. Dogan I, Mittal RK. Esophageal motor disorders: recent advances.
Curr Opin Gastroenterol 2006;22:417-422.

4. Pandolfino JE, Ghosh SK, Rice J, Clarke JO, Kwiatek MA, Kahrilas PJ. Classifying esophageal motility by pressure topography characteristics: a study of 400 patients and 75 controls. Am J Gastroenterol 2008;103:27-37.

5. Fox MR, Bredenoord AJ. Oesophageal high-resolution manometry: moving form research and into clinical practice. Gut 2008;57:405423.

6. Pandolfino JE, Kahrilas PJ. New technologies in the gastrointestinal clinic and research: impedance and high-resolution manometry. World J Gastroenterol 2009;15:131-138.

7. Sifrim D, Fornari F. Non-achalasic motor disorders of the esophagus. Best Pract Res Clin Gastroenterol 2007;21:575-593.

8. Tutuian R, Castell DO. Esophageal motility disorders (distal esophageal spasma, nutcracker esophagus, and hypertensive lower esophageal sphincter): modern management. Curr Treat Options Gastroenterol 2006;9:283-294.

9. Konturek T, Lembo A. Spasm, nuckcracker, and IEM: real or manometry findings? J Clin Gastroenterol 2008;42:647-651.

10. Lacy BE, Weiser K. Esophageal motility disorders: medical therapy. J Clin Gastroenterol 2008;42:652-658.

11. Vantrappen G, Janssen J, Hellemans J, Coremans G. Achalasia, diffuse esophageal spasm, and related motility disorders. Gastroenterology 1979;76:450-457.

12. Kramer P, Harris LD, Donaldson RM Jr. Transition from symptomatic diffuse esophageal spasm to cardiospasm. Gut 1967;8:115-119.

13. Kaye MD, Kilby AE, Harper PC. Changes in distal esophageal function in response to cooling. Dig Dis Sci 1987;32:22-27.

14. Triadafilopoulos G, Tsang HP, Segall GM. Hot water swallows improve symptoms and accelerate esophageal clearance in esophageal motility disorders. J Clin Gastroenterol 1998;26:239-244.

15. Mellow MH. Esophageal motility during food ingestion: a physiologic test of esophageal motor function. Gastroenterology 1983;85: 570-577.

16. Allen ML, Mellow MH, Robinson M. Manometry during food ingestion aids in the diagnosis of diffuse esophageal spasm. Am J Gastroenterol 1992;87:568-571. 